\title{
SOCIAL MEDIA AND FAKE NEWS ON CORONA VIRUS: A REVIEW OF LITERATURE
}

\author{
Sandra Ukwuru \\ Department of Mass Communication, \\ Nnamdi Azikiwe University, Awka, Anambra State \\ 07051045509 \\ ukwuruugwo@gmail.com \\ Prisca Nwankwo \\ Department of Mass Communication, \\ Nnamdi Azikiwe University, Awka, Anambra State \\ 07033256187 \\ nwankwoprisca1@gmail.com
}

\begin{abstract}
Social media is the 21st-century media that has given every user an equal opportunity to publish news without passing through any form of gatekeeping, editorial, or professional scrutiny. This means that it has become a natural home for the spread of fake news even on the recent coronavirus with its consequent health implications. The authors deployed available materials and literature to discuss the burning issues surrounding fake news as misleading information on social media, especially how social media has become a natural home for fake news on coronavirus. More so, this paper reviewed the literature on the effects of fake news on coronavirus and then motivations for sharing fake news online as a way to provide a start-off point for an understanding of why social media misinformation on Corona virus has spread. The authors concluded by presenting a gap in literature, in addition to a research agenda for studies on the spread of health-related disinformation in Nigeria.
\end{abstract}

Keywords: Social Media, Fake news, Corona Virus, Social Media, Misinformation

\section{INTRODUCTION}

Sharing and commenting on trending news on social networks, without taking time to verify its authenticity, have become habits synonymous with the news engagement patterns of social media users. Originators of misinformation on different social media platforms often do this to drive conversations, alter perceptions, and also draw followership for their ideology. The motivations for peddling misinformation can also be monetary gains, or even to influence expectations about the state of the world like in the case of Pentagon's Military Analysts Program (Barstow, 2008; Jowett \& O'Donnell, 2015; Foerster, 2017).

Social media is the 21 st- century media that enable interactivity from person to many. Its introduction gave equal opportunity for everyone to be a citizen journalist. However, this affordance comes with its pros and cons in the dissemination of information. Facts and unverified information are transmitted at the same time to millions of social media users.

Due to the proliferation and widespread use of social media platforms, traditional journalism faces a challenge with regard to who reports the scoop. In any case, research has shown that social media has been used to disseminate all sorts of unverified information with unprecedented speed, while the traditional journalist scampers for facts (Gelfert, 2018). As Ireton and Posetti (2018) argue, digital media has lowered the barrier to entering the information market place and that the sharing of articles on social media platforms such as 
Facebook displaces many of the traditional markers of traditional journalism (including visual markers as professional layout, an official masthead, comprehensive coverage, etc.). Undoubtedly, the recent COVID-19 pandemic seems to have deepened the discourse around health-related fake news, further raising concerns about its implications to public health. Referring to how fake news propagated online has worsened the pandemic, Director-General of WHO, Tedros Adhanom Ghebreyesus stated that the world was not just fighting a pandemic, but also an "infodemic", the global epidemic of deliberate dissemination of false information or misinformation which could involve various forms of reconfiguration, where existing and often true information is twisted, recontextualised, or reworked, or labelled as true or as being something other than they are, especially online (Mesquita, Oliveira, Seixas \& Paes, 2020; Wardle, 2017).

This paper reviews the literature on fake news on Corona virus with particular emphasis on the disinformation that linked Corona virus with 5G network and the assertions that some notable philanthropists have supported the distribution of infected face masks for use in Africa. It also reviews available literature on the effects of fake news on Corona virus, in addition to motivations for engagement with fake news to provide a start-off to an understanding of why misinformation on Corona virus has spread rapidly, and to set a research agenda for related Nigerian studies.

\section{CORONA VIRUS (COVID-19): AN OVERVIEW}

Corona virus or COVID-19 is the infectious disease which is caused by the most recently discovered Corona virus originating from Wuhan in China. This virus was reported to the WHO Country office in China on $31^{\text {st }}$ December 2019. However, the outbreak was declared a Public Health Emergency of International Concern on $30^{\text {th }}$ January 2020. Subsequently, on 11th February 2020, the World Health Organization announced a name for the new Corona virus disease (COVID-19). Following the outbreak, the World Health Organization reported that it took to work $24 / 7$ to analyze data, provide advice, coordinate with partners, help countries prepare, increase supplies, and manage expert networks.

According to the World Health Organization reports on COVID-19, most people infected with the COVID-19 virus will experience mild or moderate respiratory illness and recover without special treatment. Besides, people who are older, and those with underlying medical problems like cardiovascular disease, chronic respiratory disease, diabetes and cancer are most likely to develop severe illness. More so, since there is currently no specific vaccines for COVID-19 (though there are on-going clinical trials to evaluate potential therapies for the virus), the organization states that the best way to prevent and slow down transmission is to be well informed about the virus with regard to its symptoms, how it spreads and protective measures. As protection against infection, regular washing of hands, the use of alcohol-based sanitizers. Furthermore, people have been advised to avoid touching their faces and to practice respiratory etiquette (for example, coughing into a flexed elbow) to prevent transmission through droplets of saliva or discharge from the nose whenever an infected person coughs or sneezes (WHO, 2020). Some of these existing reliable information coming from the world's apex health body is what in the views of Wardle (2017) have been twisted, recontextualised, or reworked online. 


\section{SOCIAL MEDIA AS HOME FOR FAKE NEWS ON CORONA VIRUS}

With the social media, local issues can gain global prominence through online campaigns. As online tools, they offer a plethora of global platforms for the dissemination of information and opinion and also facilitate social interactions between individuals and organizations (Botha \& Mills, 2012). In the current Corona virus (COVID-19) scenario, social media platforms are disseminating all sorts of information globally. While the World Health Organization (WHO) and several health organizations are regularly posting and updating awareness and guidelines across a plethora of online platforms (WHO, 2020), disinformation on the disease has also been disseminated on these platforms. Sharing of misleading information is not new, and has regrettably accelerated the spread of medical misinformation in today's digital world (Perakslis \& Califf, 2019). For the spread of disinformation on Corona virus in particular, most stories on social media have been identified as fake news by the regulatory agencies (BBC, 2020).

Indeed, social media has become a platform for the dissemination of rumours and deliberate misinformation, and many are using social media sites such as Facebook, Twitter, Whatsapp, and YouTube, and to create a state of panic and confusion as false misleading, or false medical advice can travel around the world before anyone has a chance to correct it (Charlton, 2020). Currently, the world is challenged by an unprecedented crisis of public understanding, and such social media platforms as Facebook, Instagram, Twitter, YouTube, are at the center of it.

Interestingly, the dissemination of misinformation on social media can either be intentional or accidental and can spread quickly as anybody can say almost anything to anyone, with billions of individuals online daily. The spread has become heightened with multiple digital sources without editorial rules which can easily be trusted or taken seriously by social media users (Armstrong \& Naylor, 2019). These platforms can be used to facilitate as well as multiply Covid-19- related misinformation, and unfortunately, misleading posts have become popular than the ones that disseminate accurate and relevant public health information about diseases (Sharma et al., 2017). The nature of social media makes for easy sharing of information, and unlike traditional news outlets, there is no filter, no fact-checking, and often a lot of bias.

Notably, most fake news on Corona virus have centred on various conspiracy theories, resulting in a plethora of incorrect ways of looking at the situation. There are unfounded views that the virus is a biological weapon, created either by the United States (to destroy China) or China (to destroy American) in other to take over world power from America and initiate a new world order. There are also views that COVID-19 is the likely by-product of Chinese foods, like bat soups among other foods, More so, messages on unverified home remedies like the use of Vitamin $\mathrm{C}$, turmeric, cow urine, etc., to mention a few, have all been disseminated on social media.

However, in today's scenario, social media can also be responsibly and effectively utilized to disseminate regular, consistent and reliable information to achieve clarity and awareness to eliminate confusion and panic. As the fastest way to share news, social media provide access to Covid-19 news, create awareness on the virus and also draw attention to related misinformation coming in from individual states and different parts of the world to everyone who can gain from the information provided. Government officials and public leaders who are dealing with the global health crisis daily have provided accurate, scientific information 
regularly in combating misinformation and rumour. More so, WHO and other relevant public health organizations have utilized the social media as a platform for prompt dissemination of information about the outbreak to the public to control panic created by the misinformation being circulated in the social media.

Unfortunately, governments or health bodies may not always be able to respond with accurate and timely information due to various reasons. Sometimes, the evidence needed to support statements and arguments, and the standards concerned with how and why people are socially responsible for what they say is ignored. Due to the abundance of information in the digital age, it becomes difficult for people to identify truthful and trustworthy sources from false or misleading ones, and the inability of concerned authorities and experts to handle the situation has made them lose their legitimacy among the public. Therefore, social media users continue to rely on discredited misinformation (Rich \& Zaragoza, 2016).

On their part, social media websites are trying to curtail the activities of the originators of misinformation. Tools to effectively prevent the spreading of false news are utilized by the ICT giants, who are skilled in censorship. Initially, social media companies did not pay a lot of attention to checking content published on their platforms. However, over the years, they have designed a set of efficient automated and human-driven processes to edit, promote or filter published content, as these platforms have become primary sources of information for a large number of the user (Yaraghi, 2019). To dispel harmful misconceptions, developers of various social media, like WeChat, are using fact-checking platforms. More so, western social media platforms, like Facebook, Twitter and Instagram have also made efforts to ensure the amplification of right and trustable sources. People are now more unlikely to be exposed to unfounded assertions when they search for the word 'Corona virus' on these social media platforms. However, the volume of content on social media could make it impossible to edit every aspect of the content, just like in the traditional media. With no perfect set-up or filtering algorithm, many originators of disinformation now capitalize on the trending Corona virus situation.

The impact of fake news on social media platforms, during an outbreak, can be said to be more profound. Therefore, to control emerging pandemics, there is need for unique health communication and education plans by public health agencies to meet the information needs of the public regarding possible risks and preventive measures, while eliminating dramatization and exaggeration of risk (Strekalova, 2016). Social media can be useful in this regard as it can facilitate the structural, psychological, and resource empowerment processes in communities in ways that can help them achieve shared identification, group participation, and collective control (Leong, Pan, Rackham, \& Kaewkitipong, 2015). Generally, combating the spread of misinformation on Corona virus requires research that will help to understand the origin and the range of misinformation. This will facilitate well-coordinated plans that will help disrupt sources of this information in a way that can reduce its dissemination.

\section{OF 5G CORONA VIRUS AND INFECTED FACE MASKS}

Recently, the cause of Corona virus was linked to the fifth- generation of internet $(5 \mathrm{G})$ which is the next generation of mobile broadband technology (Oyewale, 2015) that will eventually replace, or at least augment the 4G LTE connection. With 5G, internet users will experience exponentially faster download and upload speeds. The time it takes devices to communicate with wireless networks will also decrease drastically with the use of 5G. Unlike LTE, 5G operates on three different spectrum bands which can dramatically improve efficiency in 
everyday internet use. It can, for example, support user download speeds of 100Mbps and uploads speeds of 50Mbps and support the connection of 1 million devices per square kilometre in a way that can power the Internet of Things (IoT) (Dahiya, 2017).

Some 5G conspiracy theorists argue that the newly developed network generates radio frequency radiation that can damage DNA and lead to cancer and premature ageing. They also contend that the network can disrupt cell metabolism, and potentially lead to other diseases through the generation of stress proteins, and Corona virus in particular by weakening the immune system. In fact, a notable Nigerian Bishop took to social media in a protest against the installation of $5 \mathrm{G}$ network in Nigeria. Though it had not been proven that 5G network is responsible for Corona virus pandemic, originators of fake news disseminated stories online that suggest that $5 \mathrm{G}$ network has a direct causal link with Corona virus (Adelakun, 2020).

With the increased panic associated with the pandemic, there were also assertions that some notable philanthropists have supported the distribution of infected face masks for use in African. This news trended in videos, pictures, and audio voice messages on Whatsapp and Facebook. However, it was evident that these messages were in fact fake news.

\section{MOTIVATIONS FOR ENGAGEMENT WITH FAKE NEWS}

The motivations for fake news production and dissemination have been a focus of research, and emanating literature is reviewed in this paper for an understanding of why individuals would want to engage with fake news on Corona virus as found on social media. Notably, there seems to be an academic consensus that, generally, the main motivations behind fake news production are commercial, political, or ideological (Hirst, 2017). On the one hand, the commercial motivations refer to the creation and dissemination of misinformation to increase the readership of a news website and consequently get more advertising revenues (Allcott \& Gentzko, 2016). For instance, in the 2016 US elections, fake news was created by teenagers in a town in Macedonia just for economic incentives. They stated that publishing pro-Trump content helped them generate more advertising revenue (Marwick \& Lewis, 2017).

On the other hand, the other motivation can be referred to as ideological, based on the manipulation and defamation of individuals to damage their public image. In this case, the objective of the originators of misinformation is to empower the individuals they favour through false information that can change public opinion. One vivid example of this phenomenon was experienced in July 2016 when the website wtoe5news.com published an article alleging that Pope Francis supported Donald Trump's presidential candidacy (Allcott \& Gentzkow, 2017). The news was shared on Facebook more than one million times and many people perceived it as true. More so, in a study conducted by Chadwick and Vaccari (2019), labour supporters and those adhering to left-wing ideological beliefs were more likely to share inaccurate news. Similarly, Petersen, Osmundsen and Arcenaux (2018) also argue that the motivations behind sharing false rumour online can be partisan - to mobilize against a political opponent - or as a way to challenge the whole political system and mobilize receivers of the disinformation against a particular political setting. Drawing on data from a study conducted in the US and Denmark, Petersen and his colleagues found the latter to be the overriding psychological motivation underpinning the sharing of false news. 
More so, some other scholars have found that the social identity of the audience can be a factor that can influence their sharing of information on social media generally. Bigman et al. (2019), for instance, found that race influences how young social media users select exposure to social media news. Black students in their study reported 'both seeing and posting more content about race on social media'. In addition, findings from their study showed that an orientation towards civic participation or purpose can be a motivation for sharing information on social media. Britons in particular, as shown in their study, stated that they shared information online to express their feelings; inform others, and find out other people's opinions.

Furthermore, Duffy, Tandoc and Ling (2019) found that individuals shared news online to cope with uncertainty, build relationships, and enhance themselves. Sharing news, according to Duffy et al. (2019), is seen as an effort toward contributing to social cohesion. According to the scholars, users doing so are motivated by the emotional impact the news is seen to have, as well as the relevance it might have for the receiver, and the sender's intention to provide advice or warning. Therefore, the trend of sharing 'fake news', according to Duffy et al. (2019) is regarded as a sign of trust between the sender and recipient. For them, what is shared is more than just news or information; it is also a signifier of trust and mutuality.

The motivation to inform others corroborates the findings of Chakrabarti et al. (2018) who seem to be some of the few researchers that have explored audiences' interaction with "fake news" in the African context. Their study explores three reasons that can help explain the sharing of "fake news" in Kenya and Nigeria. First, as findings from their study showed, there is the desire to be "in the know" socially, so sharing disinformation becomes a form of social currency. Second, as the findings from their study also showed, there is a sense of civic duty that might lead users of social media to share warnings of an imminent crisis or disaster. For the scholars, even if the information might turn out to be false, the harm caused by not informing others may be perceived as outweighing that of informing them. Third, there is the sense that information is just democratic and therefore needs to be shared (Chakrabarti et al. 2018).

Interestingly, another study on the spread of 'fake news' in the African context, (Wasserman $\&$ Morales, 2019) established a link between lack of trust in the news media and the sharing of disinformation. It was found in the study that there is a significant relationship between high levels of perceived exposure to misinformation and low levels of media trust. This corresponds with similar findings elsewhere (Chadwick \& Vaccari, 2019 in the British context) that suggest that the widespread sharing of false news may signify a growing cynicism about the accuracy of news in general.

Interestingly also, the consumption of fake news has been attributed to a general distrust and cynicism about the credibility of the news ecosystem as a whole (Wagner \& Boczkowski, 2019). According to the authors, the fake news debate echoes against a backdrop of low trust in public institutions. This, according to them, is arguably one of the reasons the term has strongly resonated with many people who have used it to criticize individuals in authority, especially politicians who tell lies.

More so, in the African context, other cultural influences like the long-standing importance of informal sources of information such as gossip, rumour, and satire (Nyamnjoh, 2005) can be said to play a further role in the likelihood of social media users to share fake news. In addition, apart from cultural influences such as the long-standing importance attached to 
informal sources of information such as gossip, rumour and satire which has aided the spread of fake news, the long history of an untrustworthy news media often owned or captured by the state or social elites, has given rise to strong alternative channels of news and information on which fake news may thrive in the African context (Wasserman \& Morales 2019).

\section{EFFECTS OF FAKE NEWS ON CORONA VIRUS}

Research has also focused on the effects of fake news on Corona virus. Unarguably, the effect of fake news on Corona virus lies in the fact that there are social media users who believe it. Unfortunately, there is evidence that $70 \%$ of the global population globally believe that the cause of Corona virus disease was the introduction of 5G networks and this means that fake news in a broader term sounds truthful until it is debunked.

Research findings show that misinformation on COVID-19 has promoted misperceptions among people in a way that causes panic and poses serious health issues. The deliberate spread of online health-related misinformation on COVID-19 was, for example, responsible for the methanol poisoning recorded in Iran (an Islamic country with strict restrictions on alcohol consumption) in March 2020, where 2100 Iranians ingested alcohol after exposure to social media messages that suggested they could prevent being infected by the virus by so doing. About 900 of the alcohol-poisoned patients were admitted into the Intensive Care Unit (ICU) out of which 296 died (Soltaninejad, 2020).

Worse still, social media users' vulnerability to false information increases as they increasingly rely on social media as a source of news. A Pew survey showed that $62 \%$ of American adults get news from social media sites such as Facebook (Gottfried \& Shearer 2017), which played an essential role in the spread of fake news on the Corona virus pandemic.

\section{GAP IN LITERATURE}

Findings from the reviewed literature show that social media has become natural home for fake news on Corona virus and that its spread has negative effects on public health. However, there seems to be a paucity of research on the effects of social media fake news on Corona virus among social media users in Nigeria, in addition to the reasons why they would engage with such news.

More so, generally, there seems to be a paucity of research that deconstructs how social media audience receive fake news since communication is one thing and reception is another. In addition, there seems to be a paucity of findings on how demographic and social factors could influence the spread and motivation for engagement with social media fake news on Corona virus, and by extension, health-related fake news. Therefore, this paper proposes a research agenda for studies on the spread of social media fake news in Nigeria based on these gaps in literature.

\section{CONCLUSION}

Although social media has increased the visibility of citizen journalists (Hermida, 2010), it has also led to the increased visibility and impact of both true and false information (Mendoza, Poblete \& Castillo, 2010). In response to health-related crisis, governments and health organizations more often than not make use of social media as opposed to traditiona 
media (Kim \& Liu, 2012). Unfortunately, despite the efforts made by these bodies to direct the public towards reliable sources for verified information and updates, health-related misinformation has thrived on social media.

In the new media age of inter-connectedness, misinformation related to the Covid-19 pandemic has spread to millions of people globally, and unfortunately, misinformation seems to spread much faster than operators of social media platforms can contain or control. Though some contents are explaining the actual situation, they are countered by a large number of false information or misinformation that misguides the public who are unaware of the real situation. Worse still, people often find it difficult to differentiate the truth from the misinformation on social media, and being the most common, quickest, and easiest way of accessing information sources, they increasingly rely on it for information (Ruohan \& Suh, 2015).

However, social media can also offer the best platforms to disseminate information if users of different social network sites transmit information from credible sources. For the dissemination of false information and fake news to be nipped in the bud, social media users need to refrain from disseminating inaccurate information and endeavour to verify and check the credibility of data to reduce the spread of health-related misinformation.

Based on the reviewed literature and identified gap, we propose a research agenda for studies on the spread of health-related disinformation in Nigeria. Researchers should first determine what Nigerian audience tag as fake news and their consumption patterns in view of the high ascendency of fake news on COVID-19. They should also explore what motivates them to consume this news. More so, it is necessary to deconstruct how audience in Nigeria receive fake news on COVID-19 and other health issues since communication is one thing and reception is another. In addition, there is a need to explore the demographic and social/cultural factors that influence engagement with fake news on COVID-19 and other health issues.

Furthermore, since available findings on audience engagement with fake news on social media have been mostly derived from quantitative methods like survey, Nigerian studies can benefit from such qualitative methods as participant observation and scroll back method (Robards \& Lincoln 2017) for in-depth findings on how social media users engage with fake news on COVID-19 and other related health issues. It is expected that findings from this study would guide the designing and dissemination of tailored or targeted health information to ensure effectiveness.

\section{REFERENCES}

Adelakun, A. (2020). Pastor Chris Oyakhilome has made history. Retrieved May 2020 from https://punchmg.com/ pastor-chris-oyakhilome-has-made-history/

Allcott, H., \& Gentzkow, M. (2017). Social media and fake news in the 2016 election. Journal of Economic Perspectives, 31(2), 211-236.

Armstrong, P. W. \& Naylor, C.D. (2019).Counteracting Health Misinformation: A Role for Medical Journals? JAMA The Journal of the American Medical Association, 321(19) April 2019 
Volume 1 Number 2

Barstow, D. (2008). Behind TV analysts, pentagon's hidden hand.

Retrieved April 20

$20 \quad$ from

https://www.researchgate.net/publication/264840220_Behind_TV_Analysts_Pentago n's_Hidden_Hand

BBC (2020). Corona virus: what misinformation has spread in Africa? Retrieved August 1, 2020 from https:www.bbc.co.uk/news/world-africa-51710617

Botha, E. \& Mills, A.J. (2012). Managing the new media: tools for brand management in social media. In a. Close (ed), Online consumer behaviour: theory and research in social media, advertising and E-tail (pp.83-100) New York: Taylor and Francis

Bigman, C.A., Smith, M.A., Williamson, L.D., Planey, A.M. \& Smith, S.M. (2019). Selective sharing on social media: Examining the effects of disparate racial impact frames on intentions to retransmit news stories among US college students. New Media \& Society. DOI: 10.1177/1461444819856574/

Chadwick, A. \& Vaccari, C. (2019). News sharing on UK social media: misinformation, disinformation, and correction. Retrieved May 5, 2020 from https://www.repository.iboro.ac.uk/articles

Chakrabarti, S., Rooney, C. \& Kweon, M. (2018). Verification, Duty, Credibility: Fake News and Ordinary Citizens in Kenya and Nigeria. London: BBC News. Retrieved May 12, 2020 from http://downloads.bbc.co.uk/mediacentre/bbc-fake-news-research-papernigeria-kenya.pdf

Dahiya, M. (2017). Need and advantages of 5G wireless communication systems. International Journal of Advanced Research in Computer Science and Management Studies, 5(6), 48-51

Duffy, A., Tandoc, E.C., \& Ling, R. (2019). Too good to be true, too good not to share: the social utility of fake news. Information, Communication \& Society. https://doi.org/10.1080/1369118X.2019.1623906

Gelfert, A. (2018). Fake News: A Definition. Informal Logic, 38(1), 84-117

Hermida, A. (2010). Twittering the news: The emergence of ambient journalism. Journalism Practice, 4(3), 297-308.

Hirst, M. (2017). Towards a political economy of fake news. The Political Economy of Communication, 5(2), 82-94

Ireton, C. \& Posetti, J. (2018). Journalism, 'fake news'\& disinformation. UNESCO. 2018. https://bit.ly/2MuELY5

Jowell, G. S. \& O'Donnell, V. (2015). Propaganda and persuasion (Sixth ed.) London: Sage Publishing.

Kim, S. \& Liu, B.F.(2012) Are All Crises Opportunities? A Comparison of How Corporate 
Volume 1 Number 2

and Government Organizations Responded to the 2009 Flu Pandemic. Journal of Public Relations Research, 24,1, 69-85, DOI:10.1080/1062726X.2012.62136

Leong, C. M. L., Pan, S.L., Rackham, P., \& Kaewkitipong, L. (2015). ICT-Enabled Community Empowerment in Crisis Response:

Marwick, A. \& Lewis, R. (2017). Media manipulation and disinformation online. Retrieved August 1, 2020 from https://www.datasociety.net/pubs/oh/DataAndSociety_ Media manipulation and disinformation online.pdf

Mendoza, M., Poblete, B., \& Castillo, C. (2010). Twitter under crisis: Can we trust what we RT? Proceedings of the First Workshop on Social Media Analytics, 2010

Mesquita, T.C., Oliveira, A., Seixas, F.L., \& Paes, A. (2020). Infodemia, fake news and medicine: science and the quest for truth. International Journal of Cardiovascular Sciences. $\quad$ Retrieved August 1, 2020 from https://www.researchgate.net/publication/341060111_Infodemia_Fake_News_and_M edicaine_Science_and_The_Quest_for_Truth/fulltext/5eab79eca6fdcc70509de990

Oyewale, W. (2015). 5G, Corona virus have no link with coming of Anti-Christ- pastor. Retrieved May 20, 2020 from http://www.punchng.com/5g-coronavirus-have-no-linkwith-coming-og-anti-christ-pastor/

Petersen, M.B., Osmundsen, M., \& Arcenaux, K. (2018). A need for chaos and the sharing of hostile political rumors in advanced democracies. Paper presented at the American Political Science Association, Boston, MA. 30 August -2 September

Rich, P. R., \& Zaragoza, M. S. (2016). The continued influence of implied and explicitly stated misinformation in news reports. Journal of Experimental Psychology: Learning, Memory, and Cognition, 42(1), 62-74

Robards, B. \& Lincoln, S. (2017) Uncovering longitudinal life narratives: scrolling back on Facebook. Qualitative Research, 17(6) 715 -730

Ruohan, L. \& Suh, A. (2015). Factors Influencing Information credibility on Social Media Platforms: Evidence from Facebook Page. Procedia Computer Science, 72, 314-328

Soltaninejad, K. (2020). Methanol mass poisoning outbreak, a consequence of COVID-19 pandemic and misleading messages on social media. The International Journal of Occupational and Environmental Medicine, 11(3)

Sharma, M. et al, (2017). Zika virus pandemic — analysis of Facebook as a social media Health information platform. American Journal of Infection Control, 2(9), 23-44

Strekalova, Y.K. (2016) Health risk information engagement and amplification on social media: news about an emerging pandemic on Facebook. Health \& Education Behaviour: the Society for Public, 44(2), 332-339

Vosoughi, S., Roy, D., Aral, S. (2018). The spread of true and false news online, Science, 
Volume 1 Number 2

359(6380), 1146-1151 DOI: 10.1126/science.aap9559

Wagner, M.C. \& Boczkowski, P.J. (2019). The reception of fake news: the interpretations of practices that shape the consumption of perceived misinformation. Digital Journalism. doi.ord/10.1080/21670811.2019.1653208

Wasserman, H. \& Morales, D. (2019). An exploratory study of 'fake news' and media trust in Kenya, Nigeria and South Africa. African Journalism Studies. Retrieved May 2, 2020 from https://doi.org/10.1080/23743670

World Health Organization. Report on Covid-19. Retrieved May, 2020 from https://www.who.int/emergencies/diseases/novelcoronavirus-2019

Wardle, C. (2017). Fake news. It's complicated. Retrieved May 2020 from https://www.medium.com/Ist-draft/fake-news-its-complicated-dOf773766c79 